\title{
Lessons from the Pandemic
}

Nathan D. Grawe

Carleton College, ngrawe@carleton.edu

Follow this and additional works at: https://digitalcommons.usf.edu/numeracy

Part of the Education Commons, and the Public Affairs, Public Policy and Public Administration Commons

\section{Recommended Citation}

Grawe, Nathan D.. "Lessons from the Pandemic." Numeracy 14, Iss. 2 (2021): Article 8. DOI: https://doi.org/10.5038/1936-4660.14.2.1404 


\title{
Lessons from the Pandemic
}

\begin{abstract}
The COVID-19 pandemic highlights the importance of quantitative literacy--for policy makers and the public at large. While all aspects of numeracy have been shown relevant to the past year, our need for broader statistical literacy appear particularly pressing. Pandemic experiences may motivate greater interest in developing numeracy skills.
\end{abstract}

\section{Keywords}

pandemic, COVID-19, numeracy, public policy, education

Creative Commons License

(c) (1) (3)

This work is licensed under a Creative Commons Attribution-Noncommercial 4.0 License

\section{Cover Page Footnote}

Nathan D. Grawe is a professor of economics at Carleton College and the executive editor of Numeracy. 
The past year makes clear that the needs of numeracy are expanding with time. While the digital revolution has made it easier for to find quantitative evidence, the availability of data has only increased the value of quantitative reasoning skills required to make meaning of the growing ocean of information.

For example, Our World in Data reports that as of early July Canada boasts the highest share of population receiving a vaccination. ${ }^{1}$ While the data underlying that claim is easily found, its meaning is ambiguous. Unlike the United States, which has prioritized completing vaccination sequences, Canada has pursued a "first doses first" strategy in which everyone who wants a vaccination gets a first dose before second doses are administered. So, while Canada has a higher vaccinated population share than the United States (68.6\% versus 54.4\%), the United States has a greater share of population that is fully vaccinated (47\% as compared to $35 \%$ ). Because early studies showed first doses to be between $60 \%$ and $70 \%$ effective (as compared to $90 \%$ effectiveness for complete vaccination) (see, for example, Bernal et al. [2021]), the Canadian strategy might yield herd immunity sooner than the United States' more conservative approach. On the other hand, the World Health Organization (2021) now notes that single-dosed vaccination is less effective against the relatively new delta variant, demonstrating that, so long as the virus finds ready hosts, the first-doses-first strategy runs additional risks that a mutation might evade the vaccine. Clearly leaders need deep numeracy skills to synthesize quantitative evidence in support of effective policy in such complex circumstances.

Moreover, individual decisions in the past year point to the value of quantitative literacy for all citizens. For example, despite possessing only shortterm information on the consequences of both the disease and vaccination (by definition, we cannot know long-term impacts of either), in free societies individuals have made vaccination choices requiring them to understand and balance a range of potential risks with limited information. Some aspects of the decision seem easier than others for people to sort out. For example, given expected life spans, short-term consequences should hold more weight for the elderly, and indeed we see higher vaccination rates in older populations. ${ }^{2}$ On the other hand, we have also witnessed difficulty in processing small-probability events such as reported side effects to vaccination. Because individual decisions create public health circumstances for us all, we cannot accept a strategy for numeracy that prioritizes education for elites destined to fill leadership roles.

The past year has also shown the importance of statistical literacy to the broader numeracy agenda. While much of quantitative literacy requires little formal mathematics (interpreting basic counts, averages, proportions, and the like goes a long way!), little sense can be made of debates surrounding vaccine approval, mask mandates, lockdowns, and other public abatement policies without

\footnotetext{
${ }^{1} \mathrm{https}: / /$ ourworldindata.org/covid-vaccinations

${ }^{2}$ https://covid.cdc.gov/covid-data-tracker/\#vaccinations
} 
a rudimentary appreciation for statistical inference. At a time when many struggle to understand percentages and ratios, the numeracy movement must grapple with how statistical literacy might be approached. (Wang [2021a; 2021b] provides nice examples of how vaccine efficacy studies can be used to teach the basics of both classical and Bayesian statistics. These contributions are welcomed by those who teach introductory statistics, but something less formal is likely required if we are to empower a broader audience with a basic understanding of statistical evidence.)

As much as we have witnessed the potential power of quantitative reasoning, the past year also demonstrates its limitations. Many of the decisions we faced involved a moral element. For example, should we mandate? Certainly, the question has a quantitative component. How effective are masks? How many infections or COVID-19 deaths might be avoided through wearing a mask? Are there other risks associated with wearing a mask? (See Walach et al. [2021] for recent work in the context of children.) Quantitative evidence bears on all of these important questions. But government mandates also necessarily infringe on freedoms requiring non-quantitative deliberations. So too the question of whether to voluntarily don a mask out of consideration for others in a public place or out of respect for private property.

The characteristics of these questions which limit the power of quantitative reasoning are hardly unique to the pandemic. Should we limit lengths of patents, reducing the incentive to innovate, if this also reduces health inequality? Should we legalize sex trades? Should we adopt additional environmental policy at the expense of the present generation-even in terms of loss of life (as can happen in poorer parts of the world when they get poorer still) - to provide to the next generation a world more like the one bequeathed to ourselves? Numeracy can speak to parts of these questions (and for some people numeracy may even speak to the whole), but for most of us these questions include aspects of right and wrong independent of quantitative evidence. Given the ubiquity such limitations, it is curious to me that I have not seen an assessment designed to capture the degree to which respondents recognize when such evidence can and cannot be of use.

So, the work goes on. Hopefully, we can use the many difficult decisions individuals have wrestled with in the past year to motivate greater interest in all facets of quantitative literacy. 


\section{References}

Bernal, Jamie Lopez, Nick Andrews, Charlotte Gower, Julia Stowe, Chris Robertson, Elise Tessier, Ruth Simmons, Simon Cottrell, Richard Roberts, Mark O'Doherty, Kevin Brown, Claire Cameron, Diane Stockton, Jim Mc Menamin, and Mary Ramsay. 2021. "Early Effectiveness of COVID-19 Vaccination with BNT162b2 mRNA Vaccine and ChAdOxl Adenovirus Vector Vaccine on Symptomatic Disease, Hospitalisations, and Mortality in Older Adults in England." medRxiv. https://doi.org/10.1101/2021.03.01.21252652

Walach, Harald, Ronald Weikl, Juliane Prentice, Andreas Diemer, Helmut Traindl, Anna Kappes, and Stefan Hockertz. 2021. "Experimental Assessment of Carbon Dioxide Content in Inhaled Air With or Without Face Masks in Heathy Children: A Randomized Clinical Trial.” JAMA Pediatrics. Published online June 30, 2021. https://doi.org/10.1001/iamapediatrics.2021.2659

Wang, Frank. 2021a. "Confidence Intervals of COVID-19 Vaccine Efficacy Rates." Numeracy 14(2): Article 7. https://doi.org/10.5038/19364660.14.2.1390

Wang, Frank. 2021b. "Using COVID-19 Vaccine Efficacy Data to Teach OneSample Hypothesis Testing." Numeracy 14(1): Article 7. https://doi.org/10.5038/1936-4660.14.1.1383

World Health Organization. 2021. "Interim Recommendations for use of the Pfizer-BioNTech COVID-19 Vaccine, BNT162b2, under Emergency Use Listing: Interim Guidance First Issued 8 January 2021 Updated 15 June 2021." https://apps.who.int/iris/bitstream/handle/10665/341786/WHO2019-nCoV-vaccines-SAGE-recommendation-BNT162b2-2021.2eng.pdf? sequence $=1$ 